\title{
Abdominal obesity as a risk factor for disability in Brazilian older adults
}

\author{
Ligiana Pires Corona $^{1, *}$, Tiago da Silva Alexandre ${ }^{2}$, Yeda Aparecida de Oliveira Duarte ${ }^{3}$ \\ and Maria Lúcia Lebrão ${ }^{4}$ \\ 'School of Applied Sciences, University of Campinas, R. Pedro Zaccaria 1300, Limeira - SP, Brazil, 13484-350: \\ ${ }^{2}$ Department of Gerontology, Universidade Federal de São Carlos, São Carlos - SP, Brazil: ${ }^{3}$ Department of Medical \\ Surgical Nursing, School of Nursing, University of São Paulo, São Paulo - SP, Brazil: ${ }^{4}$ Department of Epidemiology, \\ School of Public Health, University of São Paulo, São Paulo - SP, Brazil
}

Submitted 30 March 2016: Final revision received 8 November 2016: Accepted 5 December 2016: First published online 23 January 2017

\begin{abstract}
Objective: To assess the role of abdominal obesity in the incidence of disability in older adults living in São Paulo, Brazil, in a 5-year period.

Design: Longitudinal study, part of the SABE Study (Health, Wellbeing and Aging). We assessed the disability incidence in the period (reported difficulty in at least one activity of daily living (ADL) in 2010) in relation to abdominal obesity in 2006 (waist circumference $\geq 102 \mathrm{~cm}$ in men and $\geq 88 \mathrm{~cm}$ in women). We used Poisson regression to evaluate the association between obesity and disability incidence, adjusting for sociodemographic and clinical factors including BMI.

Setting: São Paulo, Brazil.

Subjects: Older adults ( $n$ 1109) who were independent in ADL in 2006. In 2010, 789 of these were located and re-interviewed.

Results: The crude disability incidence (at least one ADL) was 27·1/1000 personyears in the period. The incidence rate was two times higher in participants with abdominal obesity compared with those without (39.1/1000 and 19.4/1000 person-years, respectively; $P<0 \cdot 001)$. This pattern was observed in all BMI levels. In regression models, abdominal obesity remained associated with disability incidence (incidence rate ratio $=1.90 ; P<0.03$ ), even after controlling for BMI, gender, age, low grip strength, cognitive impairment, physical inactivity and chronic diseases.

Conclusions: Abdominal obesity was strong risk factor for disability, showing a more significant effect than BMI, and thus should be an intervention target for older adults. Waist measure is simple, cost-effective and easily interpreted, and therefore can be used in several settings to identify individuals at higher risk of disability.
\end{abstract}

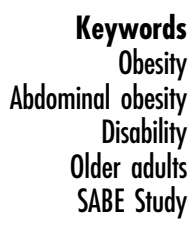

With the rapid increase in the elderly population that has been observed in recent decades, functional disability is a major concern in relation to health and care demand. The presence of disabilities is associated with higher healthcare needs and utilization compared with those with no disability, including recurrent hospitalization, greater use of outpatient care and increased risk of falls, injuries and acute illnesses ${ }^{(1,2)}$. This is an even greater concern in developing countries, since their demographic transition occurs faster and health services are not prepared to receive this growing demand ${ }^{(3)}$. Moreover, a rapid process of nutritional transition is ongoing in developing countries, with an increasing obesity and a still high proportion of underweight, which has a considerable impact on healthcare services $^{(4)}$.
Excess weight and obesity have been associated with a number of co-morbidities in all phases of life, especially chronic, non-transmittable conditions ${ }^{(5,6)}$. But in recent years, several studies have demonstrated that obesity is associated with limitations regarding physical function, independently of the presence of disease ${ }^{(4,7-13)}$. However, some results are not clear regarding obesity and disability. In a study carried out in the USA, class I obesity (BMI from 30 to $34.99 \mathrm{~kg} / \mathrm{m}^{2}$ ) proved to be a protective factor against disability in men ${ }^{(14)}$. Nevertheless, several authors suggest that BMI high values are associated with increased bone mineral density and decreased osteoporosis and hip fracture in older men and women: the increase in bone mineral density and the extra cushioning around the trochanter (outer prominence of the femur) might provide 
protection against hip fracture during a fall in obese older persons ${ }^{(15-17)}$, and thus could be protective against functional limitation after the fall.

The use of BMI is controversial in older adults. According to many authors, analysing only body weight may be a mistake, because changes in body composition may mask the real nutritional status, especially muscle wasting and fat distribution $^{(18-21)}$. Moreover, several authors have pointed out that a BMI cut-off point of $25 \mathrm{~kg} / \mathrm{m}^{2}$ may be overly restrictive for older adults and have suggested that this threshold should be raised ${ }^{(22,23)}$. Some different, more conservative, cut-offs were proposed in the literature; the most known are the one proposed by Lipschitz ${ }^{(23)}$, with an optimal range between 22 and $27 \mathrm{~kg} / \mathrm{m}^{2}$, and the one proposed by the American Committee on Diet and Health $^{(24,25)}$, between 24 and $29 \mathrm{~kg} / \mathrm{m}^{2}$.

The main problem is that obesity should be defined as the amount of excessive fat storage and although BMI is a well-accepted surrogate of body fat, body composition changes may influence its use in older adults because both weight and height may be modified with ageing. The decrease in fat-free mass and increase in fat mass, combined with height loss caused by the compression of vertebral bodies, alter the relationship between BMI and percentage body fat. In addition, there is a higher relative increase in intra-abdominal fat than in subcutaneous or total body fat with ageing ${ }^{(6,26,27)}$.

Therefore, it is important to understand if the higher risk of disability can be due to weight in general or to a higher fat concentration. The second situation can be very common in older adults with 'normal' weight, considering those changes in body composition with ageing. For instance, a study in the adult population (20-79 years) of the National Health and Nutrition Examination Survey (NHANES) showed that about $30 \%$ of men and $69 \%$ of women with BMI in the normal range had abdominal obesity ${ }^{(28)}$.

The quantification of visceral obesity is best determined by imaging examinations (such as computed tomography or dual-energy X-ay absorptiometry). The problem is that radiological measurements may not always be feasible in most clinical contexts, where anthropometric indicators are usually recommended ${ }^{(6,29)}$. Some recent studies have estimated adiposity using the waist circumference (WC) measure, which has been recommended as a better measurement for nutritional screening because it is easy to measure and strongly related to visceral and total fat ${ }^{(30-32)}$. WC is much more cost-effective and can be easily used at all health-care levels, especially in primary care, where resources may be scarce. In developing countries, like Brazil, it is important to count on cheap screening which can be effective in properly identifying people with higher risk.

Based on that, our hypothesis is that abdominal obesity can be a more informative measure and a risk marker independently from general obesity. Thus, the aim of the present study was to assess the role of abdominal obesity, measured by WC, in the incidence of disability in older adults living in São Paulo, Brazil, in a 5-year period.

\section{Methods}

\section{Sample and procedures}

The data came from the SABE Study (Health, Wellbeing and Aging), which is a longitudinal study that began in 2000 and involved a multiple-stage probabilistic sample of individuals (aged 60 years or above) who live in São Paulo ( $n$ 2143). Individuals aged 75 years or above were oversampled to compensate for the higher mortality rate in this age group. Sample weights took this oversample into consideration to represent the population. A second wave was carried out in 2006 and a third wave was conducted in 2010. In each new wave, a new sample of older adults between 60 and 64 years old was added following similar procedures used in the first wave. Details on the methodology of the study are described elsewhere ${ }^{(33,34)}$.

For the current analysis we used the second wave, carried out in 2006, as baseline ( $n$ 1413). We selected 1126 participants who were independent in activities of daily living (ADL). In 2010, 800 of them were located and reinterviewed. From the 1126 older adults selected at the baseline, seventeen did not have anthropometric measurements and were excluded. Thus, our final sample had 1109 independent older adults in 2006. Figure 1 describes the final sample.

\section{Measurements}

The 2006 and 2010 data included a household face-to-face interview conducted by a single interviewer using a standardized questionnaire addressing the living conditions and health status of the older adult respondent. Anthropometric measurements and physical tests were collected by a trained interviewer in another household visit.

The incident disability was the dependent variable and was recorded when the participant reported difficulty in one or more ADL in 2010 for which no difficulty was reported in 2006. The activities of daily living analysed were: walking across a room, dressing, bathing, feeding, transferring and toileting. Despite its importance among older adults, incontinence was not included because it does not necessarily imply physical limitation ${ }^{(35)}$.

Body weight was measured using a calibrated scale, and height was measured using stadiometer fixed to a wall, with the barefoot individual wearing light clothing. BMI $\left(\mathrm{kg} / \mathrm{m}^{2}\right)$ was calculated by dividing body mass (in kilograms) by the square of height (in metres). Nutritional status was classified based on BMI cut-off points adopted by the Pan American Health Organization for the SABE Study ${ }^{(36)}$ : $\leq 23.0 \mathrm{~kg} / \mathrm{m}^{2}=$ underweight; $>23.0$ and $<28.0 \mathrm{~kg} / \mathrm{m}^{2}=$ normal range (reference); $\geq 28.0$ and $<30.0 \mathrm{~kg} / \mathrm{m}^{2}=$ overweight; $\geq 30 \cdot 0 \mathrm{~kg} / \mathrm{m}^{2}=$ obesity. We adopted these cut-off points to 


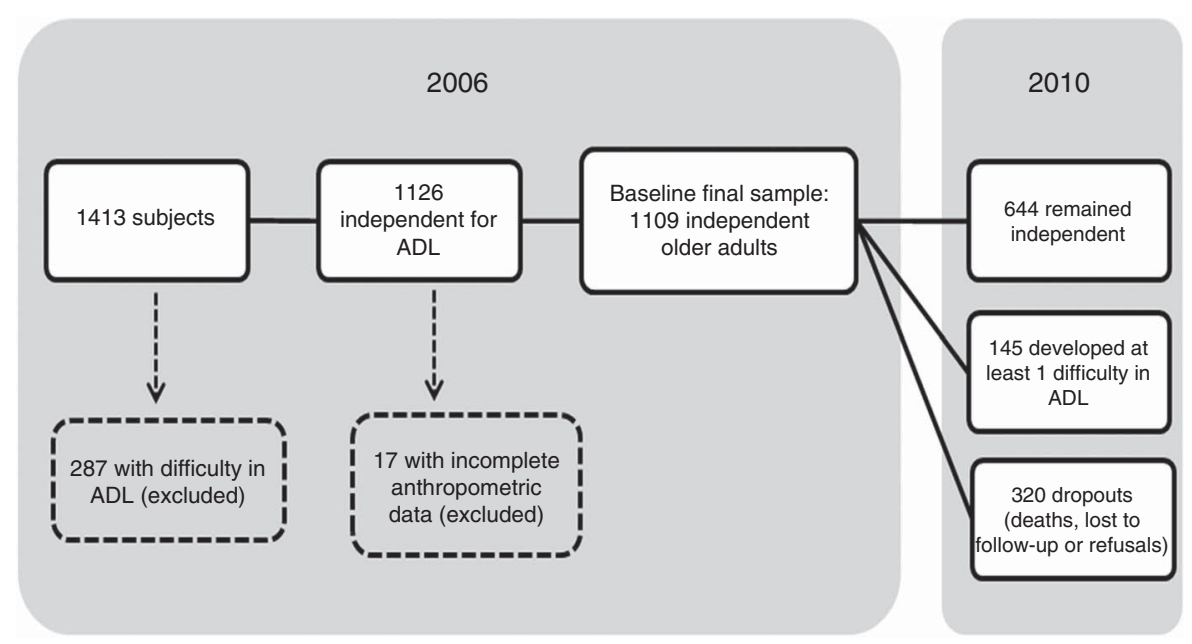

Fig. 1 Status of the SABE Study (Health, Wellbeing and Aging) sample, from 2006 baseline to the end of follow-up in 2010 (ADL, activities of daily living)

keep the same pattern of previous SABE publications and because they are really close to those proposed by Lipschitz $^{(23)}$ (i.e. the most used for older adults). Since obesity was less common than overweight and could compromise the statistical analysis due to the lower number of participants, we combined the two last categories, considering as overweight/obesity those with BMI values $\geq 28.0 \mathrm{~kg} / \mathrm{m}^{2}$.

Abdominal circumference was measured using an inelastic measure tape by a trained interviewer, at the midpoint between the last rib and the iliac crest, with the abdomen relaxed at the end of expiration, with the individual without shirt in an upright position with arms relaxed at body sides. Participants were classified with abdominal obesity when $\mathrm{WC} \geq 102 \mathrm{~cm}$ in men and $\geq 88 \mathrm{~cm}$ in women, according to the cut-offs proposed by the National Cholesterol Education Program's Adult Treatment Panel III ${ }^{(37)}$.

Sociodemographic and health-related variables measured at baseline were also included in the analysis. Baseline health status was assessed based on self-reported diabetes, hypertension, cancer, CVD, osteoarticular conditions, chronic respiratory disease and stroke.

Grip strength was measured using a dynamometer (Takei Kiki Kogyio ${ }^{\circledR}$ TK 1201), with two measurements, selecting the highest one between them. We classified low grip strength in men as values under $26 \mathrm{~kg}$ and in women as values under $16 \mathrm{~kg}^{(38)}$.

Physical activity was self-reported using the Brazilian version of the International Physical Activity Questionnaire ${ }^{(39)}$. We classified as physically inactive (sedentary) those who reported less than $150 \mathrm{~min}$ of moderate activities per week or less than $75 \mathrm{~min}$ of vigorous activities per week ${ }^{(40)}$.

Cognitive status was evaluated using a modified version of the Mini Mental State Exam validated for the SABE Study, due to the low level of schooling of the South American older adult population. This measurement has thirteen items that are less dependent upon schooling, with a total possible score of 19 points. Those with a score of 12 or lower were classified as having cognitive impairment $^{(41)}$.

\section{Statistical analysis}

For the descriptive analysis, mean values and their standard errors were calculated for continuous variables, and proportions were calculated for categorical variables. Differences between groups were estimated using the Wald test of mean equality and Rao-Scott correction, which considers sample weights for estimates with population weights.

The crude density of the incidence of disability in the 5-year period was calculated considering the participants who did not have disability at baseline. For the calculation of incidence density, the numerator was made up of the number of individuals who developed difficulty in one or more ADL in the period and the observation times were summed in the denominator. In cases of death, the observation time was the interval between the 2006 interview and the date of death. For deaths with unknown date, the observation time was the interval between the 2006 interview and a date attributed to the death based on the mean date of death of known cases in the same age group and gender. For those who did not develop disabilities, the observation time was the period between the 2006 interview and 2010 interview. For those who developed disabilities, the observation time was half the period between the 2006 and 2010 interviews. Refusals to participate, cases of institutionalization and non-located individuals also counted for half the period between the 2006 and 2010 interviews, once it was not possible to determine the date. The incidence density was also calculated according to BMI categories and for each ADL separately, according to abdominal obesity. 
Poisson multiple regression analysis was performed to evaluate the association between abdominal obesity and disability incidence in the period, incorporating those covariables with a $P$ value $<0 \cdot 20$ in the univariate regression. Variables were maintained in the final model if statistically significant $(P<0.05)$ or if they adjusted the estimates by at least $10 \%$. All analyses included sample weights and were adjusted for the complex sampling design. Data analyses were performed using the statistical software package Stata ${ }^{\circledR}$ version 12.

\section{Results}

Table 1 shows the characteristics of the participants at baseline, according to their follow-up status. Among the 1109 independent participants at baseline, mean age was 69.2 years, schooling average was 4.5 years, mean BMI was $26.6 \mathrm{~kg} / \mathrm{m}^{2}$ and mean WC was $90.8 \mathrm{~cm}$. After the 5 -year period, 146 participants died and 174 refused to participate or were lost in the period. Most of the dropouts were men, older, had lower BMI and grip strength values, lower prevalence of abdominal obesity and higher prevalence of cognitive impairment. Education, physical inactivity and self-reported chronic conditions did not differ.

Among the 789 older adults interviewed in 2010, 644 remained independent and 145 developed at least one difficulty in ADL. Participants with incident disability were older, less educated and had higher prevalence of chronic conditions at baseline, except for stroke, cardiovascular and pulmonary disease, which were not significantly associated with disability incidence. Nutritional and physical statuses at baseline were also different between groups: those who had incident disability had higher BMI and WC, lower hand grip strength, and higher proportions of obesity and abdominal obesity.

The crude incidence rate of ADL disability (at least one ADL) for all participants was $27 \cdot 1$ per 1000 person-years in the period. The incidence rate was two times higher for those with abdominal obesity in 2006 compared with those without it (39.1 and 19.4/1000 person-years, respectively; $P<0 \cdot 001)$. This pattern was observed in all BMI levels (Table 2), including normal and underweight older adults.

Table 2 also presents the incidence rate of each ADL. The activities with higher incidence were dressing, toileting and bathing, while feeding was less incident. Older adults with abdominal obesity had higher incidence in all activities, particularly in dressing and toileting, in which the rate was more than double relative to those without abdominal obesity $(P<0 \cdot 001)$.

Table 3 displays the results of Poisson regression models for the incidence of disability. In the crude models, general obesity and abdominal obesity were both

Table 1 Characteristics at baseline and after the follow-up period, according to outcome, among the sample of older adults ( $\geq 60$ years old) in São Paulo, Brazil. SABE Study (Health, Wellbeing and Aging), 2006 and 2010

\begin{tabular}{|c|c|c|c|c|c|c|c|c|c|}
\hline \multirow[b]{3}{*}{ Baseline characteristic } & \multirow{2}{*}{\multicolumn{2}{|c|}{$\begin{array}{l}\text { Total sample in } 2006 \\
\text { (baseline) }(n 1109)\end{array}$}} & \multirow{2}{*}{\multicolumn{2}{|c|}{$\begin{array}{l}\text { Dropouts (died/lost to } \\
\text { follow-up) (n 320) }\end{array}$}} & \multicolumn{5}{|c|}{ Follow-up } \\
\hline & & & & & \multicolumn{2}{|c|}{$\begin{array}{l}\text { Independent in } 2010 \\
(n \text { 644) }\end{array}$} & \multicolumn{2}{|c|}{$\begin{array}{c}\text { Dependent in } 2010 \\
(n \text { 145) }\end{array}$} & \multirow[b]{2}{*}{$P$ value* } \\
\hline & Mean & $95 \% \mathrm{Cl}$ & Mean & $95 \% \mathrm{Cl}$ & Mean & $95 \% \mathrm{Cl}$ & Mean & $95 \% \mathrm{Cl}$ & \\
\hline \multicolumn{5}{|l|}{ Gender (\%) } & & & & & \multirow[t]{3}{*}{0.039} \\
\hline Male & \multicolumn{2}{|r|}{43.0} & \multirow{2}{*}{\multicolumn{2}{|c|}{$\begin{array}{l}53.0 \\
47.0\end{array}$}} & \multicolumn{2}{|r|}{$89 \cdot 0$} & \multicolumn{2}{|r|}{$11 \cdot 0$} & \\
\hline Female & \multicolumn{2}{|r|}{$57 \cdot 0$} & & & \multicolumn{2}{|r|}{$84 \cdot 3$} & \multicolumn{2}{|r|}{$15 \cdot 7$} & \\
\hline Age (years) & $69 \cdot 2$ & $68 \cdot 1,70 \cdot 3$ & 70.7 & $69 \cdot 1,72 \cdot 2$ & $68 \cdot 2$ & $67 \cdot 1,69 \cdot 2$ & $72 \cdot 4$ & $70 \cdot 7,74 \cdot 1$ & 0.001 \\
\hline Years of schooling & 4.5 & $4 \cdot 0,5 \cdot 1$ & 4.4 & $3.8,4.9$ & 4.8 & $4 \cdot 2,5 \cdot 4$ & 3.4 & $2 \cdot 8,4.0$ & $<0.001$ \\
\hline BMI $\left(\mathrm{kg} / \mathrm{m}^{2}\right)$ & $26 \cdot 6$ & $26 \cdot 3,27 \cdot 0$ & $25 \cdot 8$ & $25 \cdot 2,26 \cdot 4$ & $26 \cdot 8$ & $26 \cdot 3,27 \cdot 2$ & $28 \cdot 1$ & $26 \cdot 9,29 \cdot 3$ & 0.055 \\
\hline Normal weight (\%) & \multicolumn{2}{|r|}{44.3} & \multicolumn{2}{|r|}{$45 \cdot 7$} & \multicolumn{2}{|r|}{45.5} & \multicolumn{2}{|r|}{33.2} & \\
\hline Underweight (\%) & \multicolumn{2}{|r|}{$21 \cdot 8$} & \multirow{2}{*}{\multicolumn{2}{|c|}{$\begin{array}{l}28.3 \\
26.0\end{array}$}} & \multicolumn{2}{|r|}{$19 \cdot 3$} & \multicolumn{2}{|r|}{$21 \cdot 3$} & 0.151 \\
\hline Overweight/obesity (\%) & \multicolumn{2}{|r|}{33.9} & & & \multicolumn{2}{|r|}{$35 \cdot 2$} & \multicolumn{2}{|r|}{$45 \cdot 5$} & 0.018 \\
\hline Waist circumference $(\mathrm{cm})$ & $90 \cdot 8$ & $89 \cdot 8,91 \cdot 8$ & 89.8 & $88 \cdot 0,91 \cdot 5$ & $90 \cdot 7$ & $89.6,91.9$ & 93.8 & $91 \cdot 1,96 \cdot 4$ & 0.041 \\
\hline Abdominal obesity (\%) & \multicolumn{2}{|r|}{$39 \cdot 2$} & \multicolumn{2}{|r|}{32.6} & \multicolumn{2}{|c|}{39.1} & & $56 \cdot 4$ & 0.003 \\
\hline Grip strength $(\mathrm{kg})$ & $25 \cdot 7$ & $24 \cdot 9,26 \cdot 4$ & $25 \cdot 6$ & $24 \cdot 1,27 \cdot 0$ & $26 \cdot 4$ & $25 \cdot 6,27 \cdot 2$ & 21.3 & $19 \cdot 7,23 \cdot 0$ & $<0.001$ \\
\hline Low grip strength (\%) & & $19 \cdot 7$ & & $25 \cdot 6$ & & 14.8 & $35 \cdot 8$ & & $<0.001$ \\
\hline Physical inactivity/sedentary (\%) & & $60 \cdot 7$ & & $63 \cdot 4$ & & 58.9 & & $72 \cdot 1$ & 0.044 \\
\hline Self-reported chronic conditions & & & & & & & & & \\
\hline Hypertension & & 59.9 & & $56 \cdot 0$ & & $59 \cdot 2$ & & 74.4 & 0.001 \\
\hline Diabetes & & $19 \cdot 3$ & & 21.9 & & $16 \cdot 6$ & & $27 \cdot 6$ & 0.010 \\
\hline Cancer & & $4 \cdot 2$ & & $6 \cdot 0$ & & $3 \cdot 0$ & & $7 \cdot 6$ & 0.024 \\
\hline Chronic pulmonary disease & & $10 \cdot 6$ & & $13 \cdot 3$ & & 9.5 & & 10.5 & 0.781 \\
\hline CVD & & 20.4 & & $21 \cdot 8$ & & $19 \cdot 1$ & & $25 \cdot 7$ & 0.087 \\
\hline Stroke & & $5 \cdot 8$ & & 7.9 & & 4.3 & & $10 \cdot 2$ & 0.070 \\
\hline Osteoarthritis & & $29 \cdot 6$ & & 23.2 & & 29.7 & & 44.9 & 0.007 \\
\hline Osteoporosis & & $19 \cdot 4$ & & $16 \cdot 2$ & & $19 \cdot 2$ & & $28 \cdot 2$ & 0.019 \\
\hline Cognitive impairment (\%) & & $7 \cdot 8$ & & 11.9 & & 4.8 & & $16 \cdot 3$ & $<0.001$ \\
\hline
\end{tabular}

Rao-Scott and Wald tests were used to assess differences.

${ }^{*} P$ value for comparison between dependent and independent in 2010 . 
Table 2 Incidence rate of disability in activities of daily living per 1000 person-years in older adults ( $\geq 60$ years old) in São Paulo, Brazil, according to the presence of abdominal obesity and BMI categories. SABE Study (Health, Wellbeing and Aging), 2006-2010

\begin{tabular}{|c|c|c|c|c|c|c|}
\hline & Total & $95 \% \mathrm{Cl}$ & $\begin{array}{c}\text { No abdominal } \\
\text { obesity }\end{array}$ & $95 \% \mathrm{Cl}$ & $\begin{array}{l}\text { Abdominal } \\
\text { obesity }\end{array}$ & $95 \% \mathrm{Cl}$ \\
\hline \multicolumn{7}{|c|}{ At least one of the activities, by BMI category } \\
\hline All participants & $27 \cdot 1$ & $22 \cdot 4,33 \cdot 0$ & $19 \cdot 4$ & $14 \cdot 7,26 \cdot 2$ & $39 \cdot 1$ & $30 \cdot 3,51 \cdot 1$ \\
\hline Normal weight & $20 \cdot 1$ & $14 \cdot 6,28 \cdot 6$ & $16 \cdot 2$ & $10 \cdot 8,25 \cdot 6$ & $33 \cdot 1$ & $19 \cdot 6,59 \cdot 7$ \\
\hline Underweight & $27 \cdot 8$ & $18 \cdot 5,43 \cdot 3$ & 27.0 & $17 \cdot 9,42 \cdot 5$ & $49 \cdot 1$ & $31 \cdot 4,60 \cdot 1$ \\
\hline Overweight/obesity & $36 \cdot 1$ & $27 \cdot 2,48 \cdot 7$ & 13.6 & $4 \cdot 9,51 \cdot 3$ & $41 \cdot 0$ & $30 \cdot 6,56 \cdot 0$ \\
\hline \multicolumn{7}{|c|}{ By type of activity, all participants } \\
\hline $\begin{array}{l}\text { Walking across a } \\
\text { room }\end{array}$ & 8.0 & $5 \cdot 7,11 \cdot 6$ & $6 \cdot 5$ & $3 \cdot 9,11 \cdot 7$ & $10 \cdot 4$ & $6 \cdot 72,16 \cdot 8$ \\
\hline Dressing & $15 \cdot 3$ & $12 \cdot 1,19.6$ & $10 \cdot 3$ & $7 \cdot 3,15 \cdot 1$ & $23 \cdot 0$ & $16 \cdot 7,32 \cdot 4$ \\
\hline Bathing & 11.2 & $8 \cdot 6,14 \cdot 8$ & 9.4 & $6 \cdot 6,13 \cdot 6$ & 14.0 & $9 \cdot 3,21 \cdot 8$ \\
\hline Feeding & 3.9 & $2 \cdot 5,6 \cdot 4$ & $3 \cdot 8$ & $2 \cdot 1,7 \cdot 4$ & $4 \cdot 1$ & $2 \cdot 1,9 \cdot 3$ \\
\hline Transferring & $10 \cdot 0$ & $7 \cdot 5,13 \cdot 6$ & 7.9 & $5 \cdot 1,12 \cdot 9$ & $13 \cdot 3$ & $9 \cdot 1,20 \cdot 1$ \\
\hline Toileting & $12 \cdot 8$ & $9 \cdot 9,16 \cdot 9$ & 8.9 & $6 \cdot 1,13 \cdot 7$ & $18 \cdot 8$ & $13 \cdot 3,27 \cdot 5$ \\
\hline
\end{tabular}

Table 3 Results of Poisson regression models for disability incidence in older adults ( $\geq 60$ years old) in São Paulo, Brazil. SABE Study (Health, Wellbeing and Aging), 2006-2010

\begin{tabular}{lrrrrr}
\hline & \multicolumn{2}{c}{ Unadjusted IRR } & & \multicolumn{2}{c}{ Adjusted IRR } \\
\cline { 2 - 3 } & IRR & $P$ value & & IRR & $P$ value \\
\hline Abdominal obesity & 1.82 & 0.003 & & 1.90 & 0.031 \\
BMI & & & & \\
$\quad$ Normal weight & 1.00 & - & & 1.00 & - \\
$\quad$ Underweight & 1.43 & 0.151 & & 1.67 & 0.032 \\
Overweight/obesity & 1.64 & 0.018 & & 1.18 & 0.535 \\
Age & 1.08 & $<0.001$ & & 1.06 & $<0.001$ \\
Gender, female & 1.43 & 0.042 & & 0.94 & 0.712 \\
Years of education & 0.91 & $<0.001$ & & 0.94 & 0.022 \\
Low grip strength & 2.60 & $<0.001$ & & 1.65 & 0.022 \\
Physical inactivity & 1.68 & 0.051 & & 1.44 & 0.205 \\
Hypertension & 1.84 & 0.013 & & 1.16 & 0.536 \\
Diabetes & 1.72 & 0.009 & & 1.33 & 0.188 \\
Cancer & 2.02 & 0.017 & & 1.69 & 0.097 \\
Osteoarthritis & 1.75 & 0.007 & & 1.61 & 0.008 \\
Osteoporosis & 1.53 & 0.019 & & 1.11 & 0.586 \\
Cognitive impairment & 2.85 & $<0.001$ & 1.46 & 0.123 \\
\hline
\end{tabular}

IRR, incidence rate ratio.

${ }^{*}$ Adjusted for age, female gender, years of schooling, low grip strength, physical inactivity, self-reported chronic conditions (hypertension, diabetes, cancer, osteoarthritis, osteoporosis) and cognitive impairment.

predictive of disability. When both variables were in the same model, controlled for the other significant factors presented in the descriptive analysis, abdominal obesity was still significant, presenting a risk 1.90 higher than for those without abdominal obesity $(P<0.03)$, and general overweight/obesity represented by BMI was no longer significant.

\section{Discussion}

Our results showed that abdominal obesity is a risk factor for disability in older adults, independent from obesity. An association between obesity and disability is already well documented in the literature ${ }^{(6-8,14,42-44)}$. In Brazil, our group had already shown that obesity was associated with higher incidence of instrumental ADL disability in a 6-year period $^{(4)}$, as well as ADL limitations and lower recovery from Nagi's limitations ${ }^{(45)}$.

A meta-analysis conducted by Carmienke et al. ${ }^{(46)}$ reported that when both BMI and WC measurements were included in the same model, BMI showed either a negative significant or an insignificant association with all-cause mortality, whereas WC showed a significant positive association with mortality when controlled for BMI. The authors recommended that abdominal obesity measurements should be used in clinical practice, in addition to BMI, to assess obesity-related mortality in adults.

Nevertheless, there are few longitudinal studies with community-living older adults, and some of them have conflicting results. A prospective study in Spain showed that the higher quintile of WC was associated with higher incidence of mobility difficulties, but not with ADL disability $^{(47)}$. Visser et al. $^{(48)}$ did not find a significant association between WC and disability in older participants from the Framingham Study (but the data were not shown in the paper). However, Chen and Guo ${ }^{(49)}$ analysed the NHANES population in the USA and found that both BMI and WC were predictive for disability in several degrees; but when in the same model, WC attenuated most of the BMI effects. Chen et al. ${ }^{(50)}$ had already shown the same effect in Hispanic older adults: when BMI and WC were included in the same model, WC, but not BMI, remained significantly associated with disability. $\mathrm{Na}$ et al. ${ }^{(51)}$ also found that BMI was not related to disability in Korean older adults and abdominal obesity increased the odds of ADL limitation by $2 \cdot 7$-fold.

Studies analysing abdominal obesity and disability are rare in developing countries. In Brazil, so far studies are cross-sectional and have small samples. Nevertheless, they already showed some associations. Campanha-Versiani et al. ${ }^{(52)}$ conducted a cross-sectional study with forty-eight women and showed that abdominal obesity was associated with lower scores in functional tests. Another 
cross-sectional study with seventy-seven older adults showed that abdominal circumference was higher in frail individuals ${ }^{(53)}$. The only study with a larger sample was a FIBRA (Frailty in Brazilian Elderly) cross-sectional multicentre study that showed that a higher WC was associated with frailty in all BMI categories ${ }^{(54)}$.

Among the possible mechanisms to explain our findings, the most cited in the literature is that obesity can represent a 'burden' for the osteomuscular system and can also increase postural instability, which can lead to higher risk of falls (particularly in abdominally obese individuals) ${ }^{(55)}$ and limit activities ${ }^{(12,47,56,57)}$. Several authors also point out that, due to the fact that abdominal obesity is highly associated with diseases that lead to disability (such as diabetes, cardiovascular conditions, cancer, etc.), this association could be confounded ${ }^{(47,51,56,58)}$; however, our results are consistent even after controlling most of those conditions, including osteoarthritis.

This higher burden that obesity could cause to the osteomuscular system may not be clear enough if only body weight is analysed; many studies have concluded that obesity was associated with higher bone mineral density and could actually prevent fractures ${ }^{(15-17)}$. But more recently the literature has been demonstrating that obesity induces chronic inflammation, which may reduce muscle mass and increase bone absorption ${ }^{(27,51,59)}$, and thus obesity could even increase risk of ankle and upper leg fractures ${ }^{(60)}$. Inflammation is already known as an important risk factor for disability, mainly mediated by its role in sarcopenia and lower physical function ${ }^{(59,61-63)}$. In this sense, it is plausible that abdominal obesity may have a role in disability modulated by inflammation, independently of chronic diseases.

Another point that should be considered is that weight loss has been widely described as a risk factor for mortality. Several studies have already shown that weight change (weight loss or weight gain) is more harmful than maintaining weight during the ageing process ${ }^{(64-67)}$. So maybe general obesity should not be targeted with severe weight-loss programmes, but abdominal obesity should be targeted to reduce risk, instead of body weight per se.

It is important to notice that, when analysing each ADL, the incidence for dressing and toileting were higher. In a study analysing SABE's first follow-up period (2000 to 2006), the most incident ADL were dressing and transferring for men and women; toileting had an incidence of $4 \cdot 3 / 1000$ persons per year for men and 10.9/1000 persons per year for women ${ }^{(68)}$. Jagger et $a l .^{(69)}$, on the other hand, found that women had higher risk of disability in bathing and toileting relative to men, but the order of activity restriction was bathing, mobility, toileting, dressing, transfers from bed and chair, and feeding. They suggested that lowerextremity disability (bathing, mobility, toileting) precedes upper-extremity disability (feeding), with difficulty for dressing being either upper-extremity or lower-extremity disability ${ }^{(69)}$. Dunlop et al. $^{(70)}$, on the contrary, argued that dressing may require only upper-extremity flexibility/ dexterity, in addition to cognitive functioning. In our point of view, dressing requires upper-limb strength, fine motor coordination, flexibility, lower-limb strength and balance $^{(68)}$, and these conditions can be strongly affected by abdominal obesity ${ }^{(54,71,72)}$.

In our study, the incidence was more than two times higher in abdominally obese older adults for the activities of both dressing and toileting. Guallar-Castillón et al. ${ }^{(47)}$ also found that the highest quintile of WC was associated with bathing or dressing difficulties in women, but not in men. So, it is plausible to understand that dressing could be affected by a 'physical barrier' such as a higher WC to cope with all those skills. The same explanation can be hypothesized for toileting in our study: the physical barrier can impact skills that can be necessary to perform this activity without help, such as flexibility, strength and mobility, and balance.

Our results should be interpreted taking some points into consideration. Disability was measured using self-reported information; nevertheless, methodological studies have demonstrated that self-reported data on functional disability have adequate validity and are consistent with medical diagnoses and/or physical tests ${ }^{(73)}$. Another limitation is the high proportion of losses, which may influence our results.

The study also has some strong points. First, it was conducted in a large representative sample of communityliving older adults in the biggest city in Brazil. Second, it is a prospective cohort that analysed only independent older adults at baseline, so it shows a possible role of abdominal obesity in the disability pathway. To our knowledge, the present study is the first one in Brazil with a large representative sample and with longitudinal follow-up.

\section{Conclusion}

Our study shows that abdominal obesity is a risk factor for disability in older adults, independently from BMI, and we consider that WC is a simple, cost-effective and easily interpreted measurement, and therefore can be used in several settings, from hospitals to primary care facilities, to identify individuals with higher risk of disability. Thus, abdominal obesity should be a target for intervention to avoid or postpone disability, cardiovascular events and mortality.

\section{Acknowledgements}

Financial support: This work was supported by São Paulo Research Foundation (Fundação de Amparo à Pesquisa do Estado de São Paulo, FAPESP) (grant number 2009/53778-3). FAPESP had no role in the design, analysis or writing of this article. Conflict of interest: None. Authorship: L.P.C. was 
responsible for study design and formulated the research question. Y.A.O.D. and M.L.L. were responsible for data collection and are Principal Investigators of the main study. The statistical analyses, results and discussion were performed by L.P.C. and T.S.A. All authors participated in the drafting of the manuscript and approved its final version. Ethics of human subject participation: This study was conducted according to the guidelines laid down in the Declaration of Helsinki and all procedures involving human subjects/patients were approved by the Research Ethics Committee at the University of São Paulo. Written informed consent was obtained from all subjects/patients.

\section{References}

1. Fried LP \& Guralnik JM (1997) Disability in older adults: evidence regarding significance, etiology, and risk. $J \mathrm{Am}$ Geriatr Soc 45, 92-100.

2. Chatterji S, Byles J, Cutler D et al. (2015) Health, functioning, and disability in older adults - present status and future implications. Lancet 385, 563-575.

3. Prince MJ, Wu F, Guo Y et al. (2015) The burden of disease in older people and implications for health policy and practice. Lancet 385, 549-562.

4. Corona LP, Pereira de Brito TR, Nunes DP et al. (2014) Nutritional status and risk for disability in instrumental activities of daily living in older Brazilians. Public Health Nutr 17, 390-395.

5. Bray GA (2004) Medical consequences of obesity. J Clin Endocrinol Metab 89, 2583-2589.

6. Zamboni M, Mazzali G, Zoico E et al. (2005) Health consequences of obesity in the elderly: a review of four unresolved questions. Int J Obes (Lond) 29, 1011-1029.

7. Jensen GL \& Friedmann JM (2002) Obesity is associated with functional decline in community-dwelling rural older persons. J Am Geriatr Soc 50, 918-923.

8. Lang IA, Llewellyn DJ, Alexander K et al. (2008) Obesity, physical function, and mortality in older adults. J Am Geriatr Soc 56, 1474-1478.

9. Alley DE \& Chang VW (2007) The changing relationship of obesity and disability, 1988-2004. JAMA 298, 2020-2027.

10. Ferrucci L \& Alley D (2007) Obesity, disability, and mortality: a puzzling link. Arch Intern Med 167, 750-751.

11. Sturm R, Ringel JS \& Andreyeva T (2004) Increasing obesity rates and disability trends. Health Aff (Millwood) 23, 199-205.

12. Vincent HK, Vincent KR \& Lamb KM (2010) Obesity and mobility disability in the older adult. Obes Rev 11, 568-579.

13. Verbrugge LM, Gates DM \& Ike RW (1991) Risk factors for disability among US adults with arthritis. J Clin Epidemiol 44, 167-182.

14. Imai K, Gregg EW, Chen YJ et al. (2008) The association of BMI with functional status and self-rated health in US adults. Obesity (Silver Spring) 16, 402-408.

15. Villareal DT, Apovian CM, Kushner RF et al. (2005) Obesity in older adults: technical review and position statement of the American Society for Nutrition and NAASO, The Obesity Society. Obes Res 13, 1849-1863.

16. Hla MM, Davis JW, Ross PD et al. (1996) A multicenter study of the influence of fat and lean mass on bone mineral content: evidence for differences in their relative influence at major fracture sites. Early Postmenopausal Intervention Cohort (EPIC) Study Group. Am J Clin Nutr 64, 354-360.

17. Felson DT, Zhang Y, Hannan MT et al. (1993) Effects of weight and body mass index on bone mineral density in men and women: the Framingham study. J Bone Miner Res 8, 567-573.

18. Hickson M (2006) Malnutrition and ageing. Postgrad Med J 82, 2-8.

19. Jackson AS, Janssen I, Sui X et al. (2012) Longitudinal changes in body composition associated with healthy ageing: men, aged 20-96 years. Br J Nutr 107, 1085-1091.

20. Seidell JC \& Visscher TL (2000) Body weight and weight change and their health implications for the elderly. Eur J Clin Nutr 54, Suppl. 3, S33-S39.

21. Cook Z, Kirk S, Lawrenson S et al. (2005) Use of BMI in the assessment of undernutrition in older subjects: reflecting on practice. Proc Nutr Soc 64, 313-317.

22. Janssen I (2007) Morbidity and mortality risk associated with an overweight BMI in older men and women. Obesity (Silver Spring) 15, 1827-1840.

23. Lipschitz DA (1994) Screening for nutritional status in the elderly. Prim Care 21, 55-67.

24. Ham RJ (1992) Indicators of poor nutritional status in older Americans. Am Fam Physician 45, 219-228.

25. Beck AM \& Ovesen L (1998) At which body mass index and degree of weight loss should hospitalized elderly patients be considered at nutritional risk? Clin Nutr 17, 195-198.

26. Villareal DT, Apovian CM, Kushner RF et al. (2005) Obesity in older adults: technical review and position statement of the American Society for Nutrition and NAASO, The Obesity Society. Am J Clin Nutr 82, 923-934.

27. Mankowski RT, Anton SD \& Aubertin-Leheudre M (2015) The role of muscle mass, muscle quality, and body composition in risk for the metabolic syndrome and functional decline in older adults. Curr Geriatr Rep 4, 221-228.

28. Okosun IS, Chandra KM, Boev A et al. (2004) Abdominal adiposity in US adults: prevalence and trends, 1960-2000. Prev Med 39, 197-206.

29. Roriz AK, Passos LC, de Oliveira CC et al. (2014) Evaluation of the accuracy of anthropometric clinical indicators of visceral fat in adults and elderly. PLoS One 9, e103499.

30. Harris TB, Visser M, Everhart J et al. (2000) Waist circumference and sagittal diameter reflect total body fat better than visceral fat in older men and women. The Health, Aging and Body Composition Study. Ann N Y Acad Sci 904, 462-473.

31. Turcato E, Bosello O, Di Francesco V et al. (2000) Waist circumference and abdominal sagittal diameter as surrogates of body fat distribution in the elderly: their relation with cardiovascular risk factors. Int J Obes Relat Metab Disord 24, 1005-1010.

32. Visscher TL, Seidell JC, Molarius A et al. (2001) A comparison of body mass index, waist-hip ratio and waist circumference as predictors of all-cause mortality among the elderly: the Rotterdam study. Int J Obes Relat Metab Disord 25, 1730-1735.

33. Andrade FCD, Guevara PE, Lebrao ML et al. (2011) Gender differences in life expectancy and disability-free life expectancy among older adults in Sao Paulo, Brazil. Womens Health Issues 21, 64-70.

34. Pires Corona L, Drumond Andrade FC, de Oliveira Duarte YA et al. (2015) The relationship between anemia, hemoglobin concentration and frailty in Brazilian older adults. J Nutr Health Aging 19, 935-940.

35. Guralnik JM \& Simonsick EM (1993) Physical disability in older Americans. J Gerontol 48, Spec. No., 3-10.

36. Organización Panamericana de la Salud (2001) Encuesta Multicéntrica. Salud Bienestar y Envejecimiento (SABE) en América Latina e el Caribe: Informe Preliminar. In XXXVI Reunión del Comité Asesor de Investigaciones en Salud, Kingston, Jamaica, 9-11 de julio de 2001. Washington, DC: División de Promoción y Protección de la Salud, OPS; available at http://envejecimiento.csic.es/documentos/ documentos/paho-salud-01.pdf 
37. National Cholesterol Education Program (NCEP) Expert Panel on Detection Evaluation, and Treatment of High Blood Cholesterol in Adults (Adult Treatment Panel III) (2002) Third Report of the National Cholesterol Education Program (NCEP) Expert Panel on Detection, Evaluation, and Treatment of High Blood Cholesterol in Adults (Adult Treatment Panel III) final report. Circulation 106, 3143-3421

38. Studenski SA, Peters KW, Alley DE et al. (2014) The FNIH sarcopenia project: rationale, study description, conference recommendations, and final estimates. J Gerontol A Biol Sci Med Sci 69, 547-558.

39. Guedes DP, Lopes CC \& Guedes JERP (2005) Reprodutibilidade e validade do Questionário Internacional de Atividade Física em adolescentes. Rev Bras Med Esporte 11, 151-158.

40. World Health Organization (2010) Global Recommendations on Physical Activity for Health. Geneva: WHO.

41. Icaza MC \& Albala C (1999) PROJETO SABE. Minimental State Examinations (MMSE) del Studio de dementia en Chile: Análisis estatístico. Investigaciones en Salud Pública, Documentos Técnicos. Washington, DC: Organización Panamericana de la Salud; available at http://www.bvsde. paho.org/texcom/cd045364/049147.pdf

42. Galanos AN, Pieper CF, Cornoni-Huntley JC et al. (1994) Nutrition and function: is there a relationship between body mass index and the functional capabilities of communitydwelling elderly? I Am Geriatr Soc 42, 368-373.

43. Rejeski WJ, Marsh AP, Chmelo E et al. (2010) Obesity, intentional weight loss and physical disability in older adults. Obes Rev 11, 671-685.

44. Gadalla TM (2010) Relative body weight and disability in older adults: results from a national survey. J Aging Health 22, 403-418.

45. Drumond Andrade FC, Mohd Nazan AI, Lebrão ML et al. (2013) The impact of body mass index and weight changes on disability transitions and mortality in Brazilian older adults. J Aging Res 2013, 905094.

46. Carmienke S, Freitag MH, Pischon T et al. (2013) General and abdominal obesity parameters and their combination in relation to mortality: a systematic review and metaregression analysis. Eur J Clin Nutr 67, 573-585.

47. Guallar-Castillón P, Sagardui-Villamor J, Banegas JR et al. (2007) Waist circumference as a predictor of disability among older adults. Obesity (Silver Spring) 15, 233-244.

48. Visser M, Harris TB, Langlois J et al. (1998) Body fat and skeletal muscle mass in relation to physical disability in very old men and women of the Framingham Heart Study. J Gerontol A Biol Sci Med Sci 53, M214-M221.

49. Chen H \& Guo X (2008) Obesity and functional disability in elderly Americans. J Am Geriatr Soc 56, 689-694.

50. Chen H, Bermúdez OI \& Tucker KL (2002) Waist circumference and weight change are associated with disability among elderly Hispanics. J Gerontol A Biol Sci Med Sci 57, M19-M25.

51. Na YM, Park HA, Kang JH et al. (2011) Obesity, obesity related disease, and disability. Korean J Fam Med 32, 412-422.

52. Campanha-Versiani L, Silveira ÉCBRd, Pimenta MC et al. (2010) Influência da circunferência abdominal sobre o desempenho funcional de idosas. Fisioterapia e Pesquisa 17, 327-331.

53. Bastos-Barbosa RG, Ferriolli E, Coelho EB et al. (2012) Association of frailty syndrome in the elderly with higher blood pressure and other cardiovascular risk factors. Am J Hypertens 25, 1156-1161.
54. Moretto MC, Alves RMdA, Neri AL et al. (2012) Relationship between nutritional status and frailty in Brazilian elderly. Rev Bras Clin Med 10, 267-271.

55. Corbeil P, Simoneau M, Rancourt D et al. (2001) Increased risk for falling associated with obesity: mathematical modeling of postural control. IEEE Trans Neural Syst Rehabil Eng 9, 126-136.

56. Houston DK, Stevens J \& Cai J (2005) Abdominal fat distribution and functional limitations and disability in a biracial cohort: the Atherosclerosis Risk in Communities Study. Int J Obes (Lond) 29, 1457-1463.

57. Rossi-Izquierdo M, Santos-Pérez S, Faraldo-García A et al. (2015) Impact of obesity in elderly patients with postural instability. Aging Clin Exp Res 28, 423-428.

58. Houston DK, Nicklas BJ \& Zizza CA (2009) Weighty concerns: the growing prevalence of obesity among older adults. J Am Diet Assoc 109, 1886-1895.

59. Cesari M, Kritchevsky SB, Baumgartner RN et al. (2005) Sarcopenia, obesity, and inflammation - results from the Trial of Angiotensin Converting Enzyme Inhibition and Novel Cardiovascular Risk Factors study. Am J Clin Nutr 82, 428-434.

60. Compston JE, Watts NB, Chapurlat R et al. (2011) Obesity is not protective against fracture in postmenopausal women: GLOW. Am J Med 124, 1043-1050.

61. Ferrucci L, Harris TB, Guralnik JM et al. (1999) Serum IL-6 level and the development of disability in older persons. J Am Geriatr Soc 47, 639-646.

62. Kuller LH (1999) Serum levels of IL-6 and development of disability in older persons. J Am Geriatr Soc 47, 755-756.

63. Cesari M, Penninx BW, Pahor M et al. (2004) Inflammatory markers and physical performance in older persons: the InCHIANTI study. J Gerontol A Biol Sci Med Sci 59, 242-248.

64. Waters DL, Ward AL \& Villareal DT (2013) Weight loss in obese adults 65 years and older: a review of the controversy. Exp Gerontol 48, 1054-1061.

65. Newman AB, Yanez D, Harris T et al. (2001) Weight change in old age and its association with mortality. J Am Geriatr Soc 49, 1309-1318.

66. Lee IM \& Paffenbarger RS (1996) Is weight loss hazardous? Nutr Rev 54, 4 Pt 2, S116-S124.

67. Nilsson PM, Nilsson JA, Hedblad B et al. (2002) The enigma of increased non-cancer mortality after weight loss in healthy men who are overweight or obese. J Intern Med 252, 70-78.

68. Alexandre TD, Corona LP, Nunes DP et al. (2012) Gender differences in incidence and determinants of disability in activities of daily living among elderly individuals: SABE study. Arch Gerontol Geriatr 55, 431-437.

69. Jagger C, Arthur AJ, Spiers NA et al. (2001) Patterns of onset of disability in activities of daily living with age. J Am Geriatr Soc 49, 404-409.

70. Dunlop DD, Hughes SL \& Manheim LM (1997) Disability in activities of daily living: patterns of change and a hierarchy of disability. Am J Public Health 87, 378-383.

71. Delmonico MJ, Harris TB, Visser M et al. (2009) Longitudinal study of muscle strength, quality, and adipose tissue infiltration. Am J Clin Nutr 90, 1579-1585.

72. Carneiro JA, Santos-Pontelli TE, Vilaça KH et al. (2012) Obese elderly women exhibit low postural stability: a novel three-dimensional evaluation system. Clinics (Sao Paulo) 67, 475-481.

73. Reuben DB, Siu AL \& Kimpau S (1992) The predictive validity of self-report and performance-based measures of function and health. J Gerontol 47, M106-M110. 